\title{
Case Report: Rare occurrence of Pseudomonas aeruginosa osteomyelitis of the right clavicle in a patient with IgA nephropathy [version 1; peer review: 2 approved]
}

\author{
Aishwarya Damodaran, Anusha Rohit, Georgi Abraham, Sanjeev Nair, \\ Anand Yuvaraj
}

Madras Medical Mission Hospital, Chennai, 600037, India

\begin{tabular}{l} 
V1 First published: 06 Nov 2014, 3:268 \\
https://doi.org/10.12688/f1000research.3891.1 \\
Latest published: 06 Nov 2014, 3:268 \\
https://doi.org/10.12688/f1000research.3891.1 \\
\hline
\end{tabular}

\section{Abstract}

We describe the case of a 47 year old patient with proven primary IgA nephropathy who presented with osteomyelitis of the medial end of the right clavicle. The patient was not on immunosuppressive medications. He underwent aspiration curettage and CT scan of the clavicle which yielded pus that grew Pseudomonas aeruginosa. Following treatment with appropriate antibiotic therapy the patient presented a complete recovery of the lesion with no loss of renal function. This case highlights the importance of positive cultures in the choice of the appropriate therapy in an extremely rare case of an immunocompetent patient with osteomyelitis of the clavicle.

\section{Keywords}

Pseudomonas aeruginosa, osteomyelitis, IgA nephropathy, antibiotics

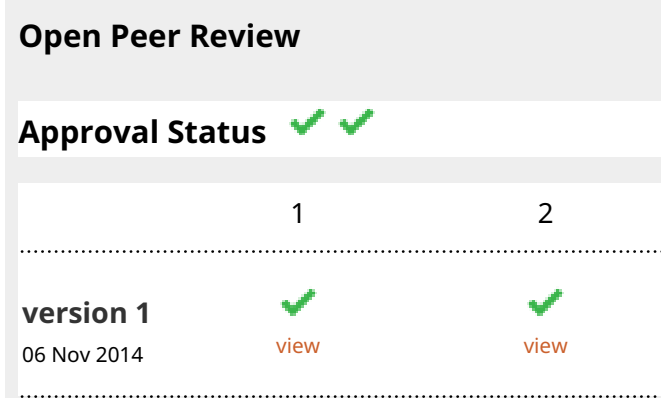

1. K V Dakshinamurthy, Nizam's Institute of Medical Sciences, Hyderabad, India

2. Kashi Nath Prasad, Sanjay Gandhi Post Graduate Institute of Medical Sciences, Uttar Pradesh, India

Any reports and responses or comments on the article can be found at the end of the article.

Corresponding author: Anusha Rohit (anu_karunasagar@yahoo.com)

Competing interests: No competing interests were disclosed.

Grant information: The author(s) declared that no grants were involved in supporting this work.

Copyright: ( 92014 Damodaran A et al. This is an open access article distributed under the terms of the Creative Commons Attribution License, which permits unrestricted use, distribution, and reproduction in any medium, provided the original work is properly cited. Data associated with the article are available under the terms of the Creative Commons Zero "No rights reserved" data waiver (CC0 1.0 Public domain dedication).

How to cite this article: Damodaran A, Rohit A, Abraham G et al. Case Report: Rare occurrence of Pseudomonas aeruginosa osteomyelitis of the right clavicle in a patient with IgA nephropathy [version 1; peer review: 2 approved] F1000Research 2014, 3 :268 https://doi.org/10.12688/f1000research.3891.1

First published: 06 Nov 2014, 3:268 https://doi.org/10.12688/f1000research.3891.1 


\section{Introduction}

Osteomyelitis of the clavicle is an extremely rare occurrence with an incidence of less than $1 \%$ in mixed age population, with Staphylococcus aureus being the most commonly isolated organism ${ }^{1,2}$. Patients often have a history of immunosuppression or invasive procedures such as tracheostomy or subclavian vein catheterisation. Here we report the case of a 47 year old man with IgA nephropathy who developed osteomyelitis of the medial end of right clavicle caused by Pseudomonas aeruginosa.

\section{Case description}

A 47 year old South Asian male teacher presented to our institute in June 2012 with a diagnosis made elsewhere of accelerated hypertension and acute left ventricular failure following a recent anterior wall myocardial infarction. He was admitted to hospital for further cardiac management, and a nephrology consultation was sought for renal insufficiency (serum creatinine $1.9 \mathrm{mg} / \mathrm{dl}$ ). The presence of an active urinary sediment (urine albumin $3+$ by dipstick and microscopic hematuria) necessitated a renal biopsy which showed IgA nephropathy (Figure 1) with an Oxford Pathological score of M1E0S1T1, 5/10 glomerular sclerosis and 30\% IF/TA with hypertensive changes in blood vessels (Figure 2). The patient was initiated on olmesartan $20 \mathrm{mg} /$ day and prednisolone $50 \mathrm{mg} /$ day and a follow up for management of proteinuria was advised.

He presented again 7 months later with swelling pain and erythema of the right clavicle that had been present for 2 months. He was evaluated for these complaints at another centre before presentation to ours and was diagnosed with synovitis of the medial end of the right clavicle. Ultrasound guided aspiration of fluid from the swelling and analysis of bacterial cultures in an external laboratory did not reveal any organism. The patient was subsequently treated with non steroidal anti inflammatory drugs and prednisolone for 1 week.

Physical examination following admission at our centre revealed a normal body mass index (BMI) and vitals with an otherwise unremarkable systemic examination. Local examination of the right

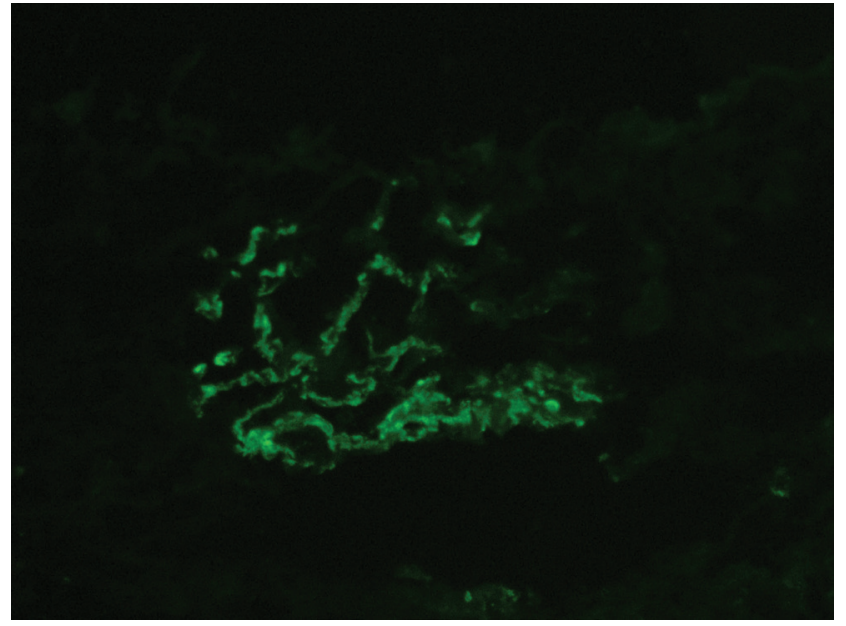

Figure 1. Immunofluorescence showing strong positive for $\lg A$ in the capillary loop and mesangium.

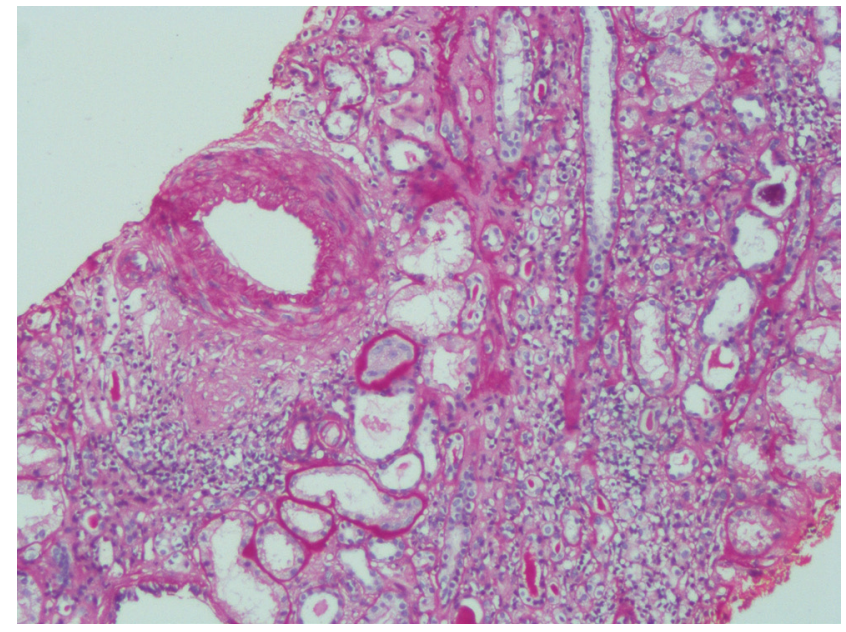

Figure 2. Hematoxylin and eosin staining showing tubular atrophy, interstitial fibrosis and thickened blood vessel.

clavicle revealed a swelling of $2 \times 3 \mathrm{~cm}$ with erythema, induration, warmth and tenderness with a firm consistency. The skin did not show discharging sinuses. Laboratory investigations revealed the following: white blood cells (WBC) count 12,400 cells $/ \mathrm{mm}^{3}$ with predominant polymorphonuclear cells, platelet count $290,000 / \mathrm{mm}^{3}$, erythrocyte sedimentation rate (ESR) $93 \mathrm{~mm} / \mathrm{hr}$, urea $42 \mathrm{mg} / \mathrm{dl}$ and serum creatinine $1.5 \mathrm{mg} / \mathrm{dl}$. Liver function tests revealed: serum glutamic oxaloacetic transaminase (SGOT) 69 IU, serum glutamicpyruvic transaminase (SGPT) $44 \mathrm{IU}$, alanine aminotransferase (ALP) $130 \mathrm{kU}$, total protein $7.3 \mathrm{~g} / \mathrm{dl}$ serum albumin $3.3 \mathrm{~g} / \mathrm{dl}$. Serology for HIV, hepatitis B and the venereal disease laboratory test (VDRL) were negative, anti-streptococcal antibody (ASO) was titre-negative, and $\mathrm{C} 3$ and $\mathrm{C} 4$ levels were within the normal range.

Urine analysis showed $1+$ albumin by dipstick, and microscopic examination of the urine showed 6-8 WBC/high power field (hpf), 2-3 epithelial cells/hpf, 4-6 RBCs/hpf and occasional granular casts. Sonography of the abdomen showed bilateral normal sized kidneys with increased echogenicity and maintained corticomedullary differentiation. Ultrasound guided aspirate of the pus from the right clavicle was cultured using BacT Alert 120 (bioMerieux, France) which showed Gram-negative and oxidase-positive rods. This suggested the presence of $P$. aeruginosa that was found to be sensitive to cefoperazone and sulbactam, using Vitek Compact II (bioMerieux, France). Repeated staining for Acid Fast Bacilli was negative. Tuberculosis (TB) PCR analysis and staining for fungal elements were negative. CT scan of the clavicle showed cortical and subcortical irregularity with soft tissue swelling of the medial end of right clavicle suggestive of osteomyelitis. Curettage and lavage of the site was followed by a gentamicin impregnated dressing (Septocoll E, Biomet Deutschland $\mathrm{GmbH}$, Berlin), and histopathological examination of the sequestrum revealed non-caseating granulomas surrounded by many neutrophils, lymphocytes and plasma cells, suggestive of chronic osteomyelitis. The patient was begun on intravenous cefoperazone and sulbactum $1.5 \mathrm{~g} \mathrm{BD}$ as per the sensitivity report for a period over 3 weeks. 


\section{Discussion}

Osteomyelitis most commonly involves the metaphyses of long bones and its occurrence in the clavicle as a primary infection is extremely rare ${ }^{1}$. The incidence of clavicular osteomyelitis in mixed adult population is less than $1 \%$ with $7 \%$ incidence in paediatric population $^{3}$, and in adults is almost always due to prior trauma or invasive procedures in close proximity to the sternoclavicular area $^{4}$. Examples of medical procedures that can cause osteomyelitis include tracheostomy, sternotomy or subclavian vein catheterisation, and osteomyelitis is often associated with immunosuppression therapy. Even in such cases the most common organism causing infection in more than $95 \%$ of the cases is $S$. aureus. In this case $P$. aeruginosa was the organism identified ${ }^{5}$.

P. aeruginosa is an aerobic, motile, non-fermenting Gram-negative bacillus which produces a biofilm. It is usually regarded as a trivial commensal of the skin, mucosa and intestinal tract, but on occasions it can be the cause of severe hospital-acquired infections. Osteoarticular infections generally include pelvic and vertebral infections in patients with primary or secondary immunodeficiency, prior to prolonged broad spectrum antibiotic therapy, vascular insufficiency, intravenous drug abuse or other invasive procedures ${ }^{6,7}$ and, when secondary to Pseudomonas spp, are associated with a greater risk of recurrence and amputation 6 . Our patient had an Ig A nephropathy treated with low dose steroid therapy for only a short while (1 week). He presented evidence of chronic renal changes such as tubular atrophy, interstitial fibrosis and blood vessel changes as shown by the biopsy. As there was no other secondary cause detected we presumed that this was a primary IgA nephropathy. The natural course of IgA nephropathy ranges from benign non-progressive disease to end stage renal failure which occurs in $15-40 \%$ of the patients over a span of 10-20 years?

The presence of osteomyelitis did not lead to rapid deterioration of renal function, as appropriate diagnosis and antimicrobial treatments were initiated without significant delay. As our patient had insignificant proteinuria, it is possible that his renal function deterioration would be slow as compared to patients with $\operatorname{IgA}$ nephropathy and heavy proteinuria.

There have been reports of reversals of secondary IgA nephropathies which developed post-chronic osteomyelitis after treating the infection ${ }^{8}$. But in this case, the diagnosis of IgA nephropathy was made 7 months prior to the onset of osteomyelitis. In this patient, there was no evidence to suggest a correlation between IgA nephropathy and profound renal insufficiency causing immunosuppression which led to osteomyelitis.

In conclusion, we report a rare occurrence of osteomyelitis of the clavicle due to $P$. aeruginosa in a non-immunosuppressed patient with chronic kidney disease and primary IgA nephropathy.

\section{Consent}

Informed written consent for publication of clinical details was obtained from the patient.

\section{Author contributions}

Aishwarya Damodaran, Georgi Abraham, Sanjeev Nair, Anand Yuvaraj: the nephrology team headed by Dr. Georgi Abraham took care of the patient.

Anusha Rohit is a clinical microbiologist who helped make the diagnosis. All authors contributed to writing the manuscript and agreed to the final content.

\section{Competing interests}

No competing interests were disclosed.

\section{Grant information}

The author(s) declared that no grants were involved in supporting this work.
1. Calhoun $\mathrm{JH}$, Manring MM, Shirtliff M: Osteomyelitis of the long bones. Semin Plast Surg. 2009; 23(2): 59-72.

PubMed Abstract | Publisher Full Text | Free Full Text

2. Carlos GN, Kesler AK, Coleman JJ, et al.: Aggressive surgical management of sternoclavicular joint infections. J Thorac Cardiovasc Surg. 1997; 113(2): 242-247.

PubMed Abstract | Publisher Full Text

3. Piazza C, Magnoni L, Nicolai P: Clavicular osteomyelitis: a rare complication after surgery for head and neck cancer. Eur Arch Otorhinolaryngol. 2006; 263(7): 653-6.

PubMed Abstract | Publisher Full Text

4. Judich A, Haik J, Rosin D, et al:: Osteomyelitis of the clavicle after subclavian vein catheterization. JPEN J Parenter Enteral Nutr. 1998; 22(4): 245-246. PubMed Abstract | Publisher Full Text

5. Balakrishnan C, Vashi C, Jackson O, et al:: Post-traumatic osteomyelitis of the clavicle: A case report and review of literature. Can J Plast Surg. 2008; 16(2): 89-91.

PubMed Abstract | Free Full Text

6. Tice AD, Hoaglund PA, Shoultz DA: Risk factors and treatment outcomes in osteomyelitis. J Antimicrob Chemother. 2003; 51(5): 1261-1268. PubMed Abstract | Publisher Full Text

7. Muñoz-Fernández S, Maciá MA, Pantoja L, et al.: Osteoarticular infection in intravenous drug abusers: influence of HIV infection and differences with non drug abusers. Ann Rheum Dis. 1993; 52(8): 570-574.

PubMed Abstract | Publisher Full Text | Free Full Text

8. Donadio JV, Grande JP: IgA nephropathy. N Eng J Med. 2002; 347(10): 738-748. PubMed Abstract | Publisher Full Text

9. Tevlin MT, Wall BM, Cooke CR: Reversible renal failure due to IgA nephropathy associated with osteomyelitis. Am J Kidney Dis. 1992; 20(2): 185-8. PubMed Abstract | Publisher Full Text 


\section{Open Peer Review}

\section{Current Peer Review Status:}

\section{Version 1}

Reviewer Report 11 December 2014

https://doi.org/10.5256/f1000research.4167.r7007

(C) 2014 Prasad K. This is an open access peer review report distributed under the terms of the Creative Commons Attribution License, which permits unrestricted use, distribution, and reproduction in any medium, provided the original work is properly cited.

\section{Kashi Nath Prasad}

Department of Microbiology, Sanjay Gandhi Post Graduate Institute of Medical Sciences, Uttar Pradesh, India

\section{General comments}

Osteomyelitis of right clavicle in an imuunocompetent individual is a rare entity that too by an opportunistic bacterium like Pseudomonas aeruginosa. Here the authors report osteomyelitis of medial end of clavicle caused by P. aeruginosa in an immunocompetent individual with IgA nephropathy. The case is interesting and it highlights the importance of prompt diagnosis of such cases and initiation of appropriate antibiotics.

\section{Specific comments}

It is not clear if the patient had any history of trauma or any invasive procedure on clavicle? Ultra sound guided aspiration was done in another hospital that did not yield any bacterial growth. Could infection by $P$. aeruginosa be iatrogenic because of earlier aspiration procedure?

P. aeruginosa was found sensitive to cefoperazone and sulbactum but what about the sensitivity to other antibiotics. Authors should provide the antibiotic profile of the isolate.

Could it be possible that IgA nephropathy and marked renal failure led to immunosuppressed state precipitating osteomyelitis?

Competing Interests: No competing interests were disclosed.

I confirm that I have read this submission and believe that I have an appropriate level of expertise to confirm that it is of an acceptable scientific standard.

Reviewer Report 12 November 2014

https://doi.org/10.5256/f1000research.4167.r6662 
(c) 2014 Dakshinamurthy K. This is an open access peer review report distributed under the terms of the Creative Commons Attribution License, which permits unrestricted use, distribution, and reproduction in any medium, provided the original work is properly cited.

\section{K V Dakshinamurthy}

Department of Nephrology, Nizam's Institute of Medical Sciences, Hyderabad, India

This is an interesting and informative article. It however needs clarification regarding the statement that this patient is non-immunosuppressed. This patient is a patient of chronic kidney disease, which by itself is an immunosuppressed state. He received prednisolone at a dose of 50 mg per day after the diagnosis of IgA nephropathy. The duration of therapy was not mentioned. Prednisolone therapy produces a state of immunosuppression. He presented again 7 months later with swelling pain and erythema of the right clavicle that had been present for 2 months. Therefore the infection occurred in an immunosuppressed individual.

Competing Interests: No competing interests were disclosed.

\section{I confirm that I have read this submission and believe that I have an appropriate level of expertise to confirm that it is of an acceptable scientific standard.}

The benefits of publishing with F1000Research:

- Your article is published within days, with no editorial bias

- You can publish traditional articles, null/negative results, case reports, data notes and more

- The peer review process is transparent and collaborative

- Your article is indexed in PubMed after passing peer review

- Dedicated customer support at every stage

For pre-submission enquiries, contact research@f1000.com 